\title{
The androgen receptor drives the sex-specific expression of vascular cell adhesion molecule- 1 in endothelial cells but not lipid metabolism genes in monocyte-derived macrophages
}

\author{
Kristine C.-Y. McGrath ${ }^{1}$, Michelle D. Hill ${ }^{1,2}$, \\ Lucinda S. McRobb ${ }^{1}$ and Alison K. Heather ${ }^{1,3, *}$ \\ ${ }^{1}$ The Heart Research Institute, Sydney, Australia \\ 2 The University of Sydney, Sydney, Australia \\ ${ }^{3}$ Department of Medical and Molecular Biosciences, \\ The University of Technology, Sydney, Australia
}

\begin{abstract}
Background: Anecdotal evidence suggests that male sex hormones are proatherogenic. We hypothesized that the male sex hormone receptor, the androgen receptor (AR), acts as a molecular switch in sex-specific inflammatory signaling in vascular cells.

Materials and methods: AR expression in human umbilical vein endothelial cells (HUVECs), human monocyte-derived macrophages (MDMs) or HeLa cells was modulated by transfection with AR siRNA or human AR cDNA expression vector. Activity and expression levels were measured by luciferase reporter assays, Western blotting or real-time PCR analysis.

Results: AR knockdown reduced expression of vascular cell adhesion molecule-1 (VCAM-1) in genetically male HUVECs. Conversely, AR upregulation in genetically female HUVECs induced VCAM-1 expression and increased dihydrotestosterone-stimulated monocyte adhesion. Co-transfection of an AR expression vector with VCAM-1 or NF-кB-reporter vectors into phenotypically female, AR-negative HeLa cells confirmed AR regulation of VCAM-1 expression as well as AR activation of NF- $\mathrm{B}$. AR upregulation was not sufficient to increase ICAM-1 levels in female HUVECs or lipoprotein metabolism gene expression in female MDMs, despite AR knockdown limiting expression in their male counterparts.

Conclusions: AR acts as a molecular switch to induce VCAM-1 expression. Low AR levels in female HUVECs limit NF-кB/VCAM-1 induction and monocyte adhesion and could contribute to the gender bias in cardiovascular disease. Unidentified factors in female cells limit induction of other proatherogenic genes not primarily regulated by NF-кB.
\end{abstract}

Keywords: androgen receptor; inflammation; nuclear factor$\kappa \mathrm{B}$; vascular cell adhesion molecule-1.

*Corresponding author: Dr. Alison K. Heather, Department of Medical and Molecular Biosciences, The University of Technology, PO BOX 123 Broadway, N.S.W. 2007 Australia Phone: +61-2-9514-2000, Fax: +61-2-9514-1551,

E-mail: Alison.Heather@uts.edu.au

Received October 3, 2009; accepted January 12, 2010;

previously published online May 18, 2010

\section{Introduction}

In all developed countries, men have an earlier and greater incidence of cardiovascular disease than that found in agematched women (1). Studies have clearly defined a protective role for female hormones in this dichotomy (2), however, the role of male hormones, or androgens, remains ambiguous. Anecdotal evidence suggests that androgens are proatherogenic (3), yet this has not been upheld in animal studies examining effects on early lesion development (4-6). It has been shown in vitro that androgens can modulate two key processes in early lesion formation that could contribute to the male predisposition to atherosclerosis. The potent nonaromatizable androgen, dihydrotestosterone (DHT), has been shown to increase monocyte-endothelial cell adhesion via upregulation of vascular cell adhesion molecule-1 (VCAM-1) $(7,8)$. DHT also stimulates intracellular cholesterol ester accumulation in monocyte-derived macrophages (MDMs) and increases the rate of cholesterol ester hydrolysis (9), critical processes leading to foam cell formation (10).

An important facet of these findings was the ability of DHT to stimulate these effects in a sex-specific manner. Published data from this laboratory has shown that DHT (4-400 nmol/L) dose-dependently induces VCAM-1 expression in male, but not female, endothelial cells (ECs) $(7,11)$. Similarly, DHT (4-400 nmol/L) enhances cholesteryl ester uptake in MDMs from male, but not female, donors (8) in conjunction with sex-specific induction of genes involved in lysosomal degradation (lysosomal acid lipase or LAL) and post-lysosomal processing [acyl coA: cholesterol acyltransferase 1 (ACAT1) and hormone-sensitive lipase (HSL)] (9). Sex-specific effects in both MDMs and ECs correlates with higher expression of the cognate receptor for androgen action, the androgen receptor (AR), in male-derived cells compared to female-derived cells $(7,12)$ and the higher AR expression in male ECs was associated with higher basal levels of VCAM-1 expression (7). Both DHT-induced VCAM-1 expression in male ECs $(7,8)$ and cholesterol ester accumulation in male MDMs (12) could be blocked by the AR antagonist, hydroxyflutamide (HF), consistent with an AR-dependent mechanism. Differential AR expression between the sexes could therefore underlie the gender-specific effects of DHT on both monocyte adhesion and foam cell formation.

We postulate the AR is the molecular switch in males driving the sex-specific effects of DHT on VCAM-1 expression, monocyte adhesion and cholesterol ester accumulation, and that low levels of cellular AR in females confers protection from these proatherogenic androgen effects. The aims 
of this study were therefore to investigate the ability of AR overexpression in genetically female ECs and MDMs to promote these responses.

\section{Materials and methods}

\section{Plasmids}

The AR expression vector, pSVARo, was provided by Professor Albert O. Brinkmann (Department of Endocrinology and Reproduction, Erasmus University Rotterdam, The Netherlands) (13). An AR short interfering RNA (AR siRNA) expression plasmid was purchased from Millipore (Millipore, Billerica, MA, USA). pZEOSV2 ${ }^{+}$ was purchased from Invitrogen (Invitrogen Corporation, Carlsbad, CA, USA). pNF-кB-luciferase and pRL-TK (used as a control for transfection efficiency) were purchased from Promega (Promega Corporation, Madison, WI, USA). VCAM-1 promoter (F2)-luciferase reporter vector was constructed as previously described (7).

\section{Cell culture}

Human umbilical vein endothelial cells (HUVECs) were isolated from male or female infant umbilical cords by the collagenase dispersion method as described previously (14) and maintained in phenol-red free M199 supplemented with 20\% charcoal-stripped human serum, $0.5 \%$ EC growth promoter, $100 \mathrm{U} / \mathrm{mL}$ penicillin and 100 $\mu \mathrm{g} / \mathrm{mL}$ streptomycin. EC monolayers were propagated on gelatincoated flasks (8), passaged by trypsinization at $90 \%$ confluency and used at passages 2-4. HeLa cells (ATCC, Manassas, VA, USA) were maintained in RPMI 1640 medium supplemented with $10 \%$ charcoal-stripped fetal bovine serum and seeded at $1 \times 10^{5} \mathrm{cells} / \mathrm{cm}^{2}$ in 12-well plates for transfection experiments. Human monocytes were isolated from white cell concentrates (buffy coats) from the peripheral blood of healthy human volunteers (Red Cross Blood Bank) as described previously (15). The monocytes were used immediately for the monocyte-adhesion assays or plated onto 12-well plates at $1 \times 10^{5} \mathrm{cells} / \mathrm{cm}^{2}$ and cultured in phenol red-free RPMI 1640 medium supplemented with $20 \%$ charcoal-stripped human serum for a 10-day period to allow monocyte-macrophage differentiation. Treatments consisted of medium containing $0.1 \%$ ethanol as control (used to dissolve DHT); (ii) DHT $400 \mathrm{nmol} / \mathrm{L}$; (iii) DHT $400 \mathrm{nmol} / \mathrm{L}+\mathrm{HF} 4 \mu \mathrm{mol} / \mathrm{L}$ and HF $4 \mu \mathrm{mol} / \mathrm{L}$. Cells were treated with DHT at $400 \mathrm{nmol} / \mathrm{L}$ only, as we have previously published that this dose elicits maximal effects on both cell adhesion and macrophage lipid accumulation and yet reflects those seen at the more physiological doses of 4 and $40 \mathrm{nmol} / \mathrm{L}(7,8,12)$.

\section{Transient cell transfections and luciferase measurements}

One day before transfection, HeLa cells were seeded at $1 \times 10^{5}$ cells per well in a 12-well plate. Cells were transfected with GenePORTER 2 (Genlantis, San Diego, CA, USA, $5 \mu \mathrm{L}$ ), serum-free M199 $(20 \mu \mathrm{L})$ and plasmid mix diluted in DNA diluent $(25 \mu \mathrm{L})$. The plasmid mixes used were: (i) pNF-кB-luciferase $100 \mathrm{ng}+$ pZEOSV2 $^{+} 100 \mathrm{ng}$ (a control plasmid to make up total plasmid DNA to $200 \mathrm{ng}$ ) + pRL-TK $40 \mathrm{ng}$; (ii) pNF-кB-luciferase $100 \mathrm{ng}+$ pSVARo $100 \mathrm{ng}+\mathrm{pRL}-\mathrm{TK} 40 \mathrm{ng}$; (iii) pVCAM-1(F2)-luciferase $100 \mathrm{ng}+\mathrm{pZEOSV}^{+} 100 \mathrm{ng}+\mathrm{pRL}-\mathrm{TK} 40 \mathrm{ng}$; (iv) pVCAM-1(F2)luciferase $100 \mathrm{ng}+$ pSVARo $100 \mathrm{ng}+\mathrm{pRL}-\mathrm{TK} 40 \mathrm{ng}$. The plasmidGenePORTER 2 suspensions were incubated with cells for 4-6 h, were then washed with phosphate buffered saline (PBS) before $1 \mathrm{~mL}$ fresh medium was added and cells were incubated for a further
48 h. Cells were lysed with passive lysis buffer ( $250 \mu \mathrm{L} /$ well; Promega) and analyzed for luciferase and renilla activity using the Dual-Luciferase Reporter System (Promega).

HUVECs were seeded $\left(1 \times 10^{5}\right.$ cells/well $)$ in a 12 -well plate. To silence AR expression in HUVECs from male donors, a mixture of $8 \mu \mathrm{g}$ of AR siRNA plasmid, serum-free M199 $(20 \mu \mathrm{L})$ and GenePORTER2 $(5 \mu \mathrm{L})$ was prepared and transfection performed (Genlantis). After $16 \mathrm{~h}$ incubation, cells were washed twice with PBS, $1 \mathrm{~mL}$ fresh medium was added and the cells were incubated for a further $24 \mathrm{~h}$. Total RNA was then harvested from the cells for real-time PCR analysis. To increase AR expression in HUVECs from female donors, $3 \times 10^{6}$ cells in log phase were suspended in a 0.4-cm electroporation chamber containing $800 \mu \mathrm{L}$ cold opti-MEM (Invitrogen), AR expression plasmid (2.5 $\mu \mathrm{g}$ pSVARo) and DEAEDextran $(4 \mu \mathrm{g})$ and transfected by electroporation (exponential decay of $250 \mathrm{~V}$ and $960 \mu$ Farads). After electroporation, cells were seeded $\left(1 \times 10^{5}\right.$ cells/well $)$ in a 12-well plate and incubated for $24 \mathrm{~h}$. The following day, cells were washed twice with PBS and refreshed with treatment medium containing $0.1 \%$ ethanol, DHT $400 \mathrm{nmol} / \mathrm{L}$, DHT $400 \mathrm{nmol} / \mathrm{L}+\mathrm{HF} 4 \mu \mathrm{mol} / \mathrm{L}$ or HF $4 \mu \mathrm{mol} / \mathrm{L}$. Total RNA was harvested from cells after $48 \mathrm{~h}$ of treatment and analyzed by realtime PCR.

Overexpression of AR in genetically female human monocytederived macrophages (HMDMs) was performed by transfection of the HMDMs on days $7-8$ with pSVARo $(0.3 \mu \mathrm{g})$ and $5 \mathrm{mg} / \mathrm{mL}$ DEAE-Dextran for $30 \mathrm{~min}$ at $37^{\circ} \mathrm{C}$. Medium $(1.5 \mathrm{~mL})$ was then added to the cells and cells were incubated for a further $1.5 \mathrm{~h}$ after which time the growth medium was changed and the cells were incubated for a further $24 \mathrm{~h}$. The transfected cells were subsequently treated with either vehicle control $(0.1 \%$ ethanol $)$ or DHT ( $400 \mathrm{nmol} / \mathrm{L}$ ) for $24 \mathrm{~h}$ before harvesting total RNA for real-time PCR analysis.

\section{Real-time PCR}

Total RNA was extracted from cells using TRI reagent (SigmaAldrich, Castle Hill, NSW, Australia) and the concentration normalized to $100 \mathrm{ng} / \mu \mathrm{L}$ using the SYBR Green II assay (Molecular Probes, Invitrogen, Melbourne, Australia). Specific cDNA was reverse transcribed from $100 \mathrm{ng}$ of total RNA using iSCRIPT (BioRad, Regents Park, NSW, Australia), according to the manufacturer's protocol. An aliquot of each cDNA sample $(1.2 \mu \mathrm{L})$ was amplified by real-time PCR in reaction mixtures containing primers (12 pmol each) and iQ SYBR Green Supermix. Amplification was performed in an iCycler iQ thermocycler (Bio-Rad) with thermal cycle conditions: $95^{\circ} \mathrm{C}$ for $3 \mathrm{~min}$, followed by 35 cycles at the annealing temperature of specific primer sets $\left(T_{\mathrm{m}}\right)$ for $30 \mathrm{~s}$ and $72^{\circ} \mathrm{C}$ for 30 s (Table 1). Relative changes in mRNA gene expression between treatments were determined by the "Delta-delta" comparative $\left(\Delta \Delta \mathrm{C}_{\mathrm{T}}\right)$ method (16) and normalized using the reference genes, $18 \mathrm{~S}$ and $\beta 2$-microglobulin. Primer sequences are listed in Table 1.

\section{Western blot analysis}

Whole protein lysate was extracted from HUVECs. Briefly, cells were harvested with trypsin and washed with cold PBS after centrifugation. Cells were lysed by the addition of RNA lysis buffer and then incubated on ice for $20 \mathrm{~min}$. Cell lysate was cleared by centrifugation and the supernatant collected for protein estimation. SDS-PAGE in $8 \%$ polyacrylamide resolving gels was used to separate total protein according to size (Bio-Rad electrophoresis unit). Resolved protein samples were transferred to PVDF membranes in transfer buffer at $30 \mathrm{~V}$ overnight in the cold room or $70 \mathrm{~V}$ for $3 \mathrm{~h}$ at room temperature. Membranes were then blocked with 5\% skim 
Table 1 Primer sequences for real-time PCR.

\begin{tabular}{|c|c|c|}
\hline Gene & Sequence & $T_{\mathrm{m}},{ }^{\circ} \mathrm{C}$ \\
\hline VCAM1-F & ATG TAG TGT CAT GGG CTG TG & 60 \\
\hline VCAM1-R & GGA ATG AGT AGA GCT CCA CC & \\
\hline ICAM1-F & CCA TCT ACA GCT TTC CGG CGC & 60 \\
\hline ICAM1-R & CTC TGG GGT GGC CTT CAG CA & \\
\hline AR-F & CAA AAG AGC CGC TGA AGG GAA ACA & 55 \\
\hline AR-R & TTC TTC AGC TTC CGG GCT CCC AGA & \\
\hline ACAT1-F & AGT TGA CAG CAG AGG CAG AG & 55 \\
\hline ACAT1-R & GGA TAA AGA GAA TGA GGA GGG & \\
\hline LAL-F & GCA ACA GCA GAG GAA ATA C & 59 \\
\hline LAL-R & GAG AAT GAC CCA CAT AAT ACA C & \\
\hline Caveolin-2-F & TGC AGA CAA TAT GGA AGA G & 59 \\
\hline Caveolin-2-R & GAA ATG AAC AGA ACA GTG G & \\
\hline HSL-F & CCG ACT TCC TCC GGG AGT AT & 59 \\
\hline HSL-R & GTC TCG TTG CGT TTG TAG TGC T & \\
\hline $18 \mathrm{~S}-\mathrm{F}$ & CGG CTA CCA CAT CCA AGG AA & 60 \\
\hline $18 \mathrm{~S}-\mathrm{R}$ & GCT GGA ATT ACC GCG GCT & \\
\hline B2M-F & GGC TCG CTT CGT GGC CTT GG & 60 \\
\hline B2M-R & TTT CAA TCT GGG GTG GAT GGA ACC C & 59 \\
\hline
\end{tabular}

Primer sequences that were used for real-time PCR obtained using Beacon Designer software. VCAM-1, vascular cell adhesion molecule1; ICAM-1, intercellular cell adhesion molecule-1; AR, androgen receptor; ACAT-1, acyl coA: cholesterol acyltransferase 1; LAL, lysosomal acid lipase; HSL, hormone sensitive lipase; 18S, 18 ribosomal S RNA; B2M, $\beta 2$-microglobulin.

milk powder in Tris buffered saline Tween-20 (TBST) for $1 \mathrm{~h}$, washed with TBST $(3 \times)$ before overnight incubation with human monoclonal AR antibody (1:500 dilution, AR441/sc7305, Santa Cruz Biotechnology, Santa Cruz, CA, USA). Membranes were then washed in TBST $(3 \times)$ and incubated with secondary antibody conjugated to horseradish peroxidase for $2 \mathrm{~h}$ at room temperature. The membrane was then washed three times with TBST, and immunodetection was accomplished with enhanced chemiluminescence (Amersham Biosciences, Castle Hill, NSW, Australia). Membranes were directly digitized and band densities measured using Quantity One Software (Bio-Rad).

\section{Cell adhesion assay}

HUVECs from female donors (transfected with the AR expression plasmid as described above) were seeded in gelatin-coated 12-well plates at $1 \times 10^{5}$ cells $/ \mathrm{mL}$ for $24 \mathrm{~h}$ before exposure to the following treatments: (1) $0.1 \%$ ethanol and (2) DHT $400 \mathrm{nmol} / \mathrm{L}$. After the treatment period, monocyte-endothelial cell adhesion assays were performed as described previously (8).

\section{Statistical analysis}

Results are reported as mean \pm SEM. Statistical significance between groups was assessed using the unpaired two-sided Student's t-test. Multiple comparisons were performed using one-way analysis of variance (ANOVA) and Bonferroni's post-hoc analysis where appropriate. A p-value $<0.05$ was considered statistically significant.

\section{Results}

\section{AR upregulation in female cells increases VCAM-1 but not ICAM-1 expression}

Genetically female ECs express relatively little AR protein compared to male ECs (Figure 1). To determine whether the absence of DHT-mediated induction of VCAM-1 expression observed previously in female-derived ECs (7) is a consequence of low AR expression, female-derived HUVECs were transfected with an AR expression vector (pAR). AR expression noticeably increased in transfected versus nontransfected cells. Elevated AR levels led to a 2.3-fold increase in VCAM-1 expression ( $\mathrm{p}<0.05$ compared to nontransfected controls) but had no significant effect on ICAM1 expression (Figure 2A). We next determined, whether the AR-induced increase in VCAM-1 expression in femalederived cells was associated with an increase in monocyte binding. One of the earliest pathogenic events in the development of atherosclerosis is the binding of monocytes to the endothelium, orchestrated by increased expression of VCAM-1 on the cell surface of endothelial cells. Monocyteendothelial cell adhesion assays were performed on female HUVECs transiently transfected with the AR expression vector (pSVARo) then exposed to vehicle or DHT (400 $\mathrm{nmol} / \mathrm{L}$ ). In female HUVECs, overexpression of AR alone did not significantly increase monoctye adhesion, however,

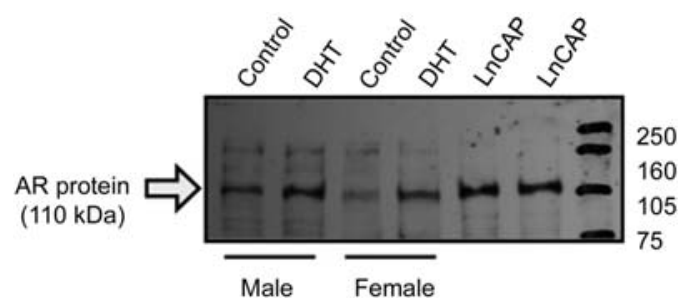

Figure 1 Male-derived endothelial cells express more AR than female-derived endothelial cells.

Total protein was isolated from male- or female-derived HUVECs or prostate cancer cells (LnCAP, positive control) and Western blot analysis used to probe for AR expression. 
in the presence of DHT-liganded AR, monocyte adhesion increased dramatically $(20 \%, \mathrm{p}<0.05$ vs. non-treated transfected controls) (Figure 2B). DHT failed to increase monocyte adhesion in non-transfected female HUVECs, therefore highlighting that AR-induced VCAM-1 expression leads to a physiologically significant atherogenic endpoint.

\section{AR silencing in male ECs reduces both VCAM-1 and ICAM-1 expression}

To test that the converse is also true, that lowering AR expression decreases VCAM-1 expression, male-derived HUVECs were transfected with siRNA targeting AR mRNA. It was demonstrated that a 2.4-fold reduction in AR mRNA levels $(\mathrm{p}<0.005$ compared to non-transfected controls) led to a 7.7-fold reduction in VCAM-1 expression $(\mathrm{p}<0.005$ compared to non-transfected controls) and a 1.5 -fold reduction in ICAM-1 expression ( $\mathrm{p}<0.05$ compared to non-transfected controls) (Figure 3), unequivocally demonstrating a
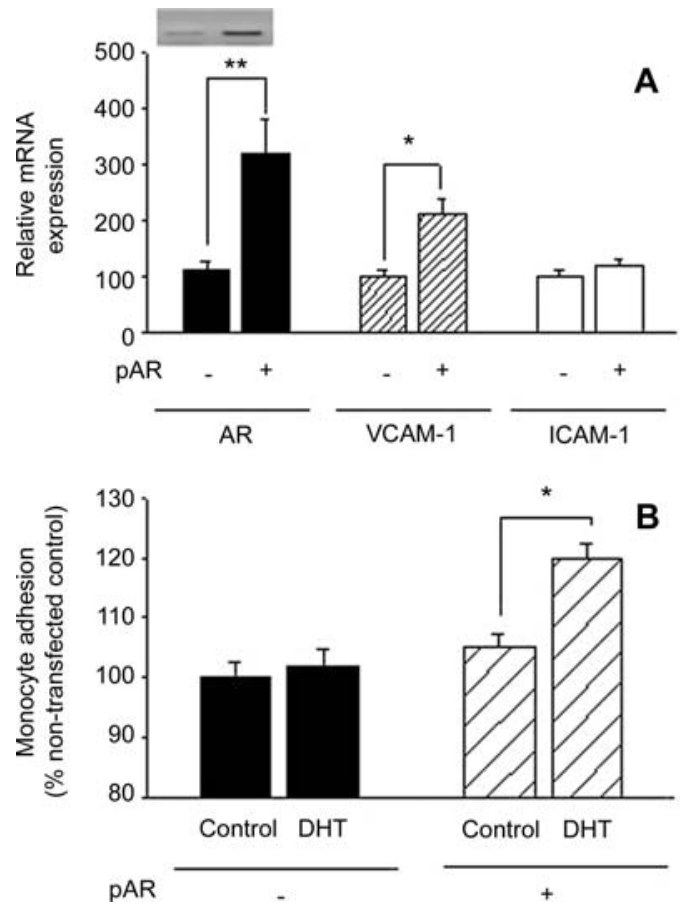

Figure 2 Increased AR expression levels induce VCAM-1 and ICAM-1 expression.

(A) Total RNA was extracted from female-derived HUVECs transfected with an AR expression vector (pAR) and RT-PCR was used to measure AR, VCAM-1 and ICAM-1 expression. Inset, AR protein levels in non-transfected (lane 1) and pAR-transfected (lane 2) female-derived HUVECs. Results are expressed as mean \pm SEM of relative expression value $(\%)$ obtained from triplicate values from two female donors. $* \mathrm{p}<0.05, * * \mathrm{p}<0.005$ vs. sex-specific nontransfected control (one-way ANOVA with Bonferroni's post-hoc analysis). (B) AR overexpression enhances DHT-induced monocyteendothelial cell adhesion to female-derived cells. HUVECs isolated from female donors were transfected with an AR expression vector (pAR) and exposed to $0.1 \%$ ethanol (vehicle control) or DHT $400 \mathrm{nmol} / \mathrm{L}$ (DHT) for $48 \mathrm{~h}$. $* \mathrm{p}<0.05 \mathrm{vs}$. female non-transfected control (one-way ANOVA with Bonferroni's post-hoc analysis). role for the AR in VCAM-1 and ICAM-1 expression in malederived ECs.

\section{AR upregulation in phenotypically female cells increases NF- $\mathrm{B}$ activity}

To investigate the findings in female cells further, HeLa cells which are phenotypically female and do not express AR were transiently transfected with an AR expression vector (pSVARo) and a VCAM-1 promoter luciferase reporter construct. AR expression in HeLa cells increased VCAM-1 promoter activity 1.7 -fold $(\mathrm{p}<0.05$ compared to nonpSVARo transfected controls) (Figure 4) showing that increased AR was activating VCAM-1 gene transcription.

As we previously identified that DHT-stimulated AR activates $\mathrm{NF}-\kappa \mathrm{B}$ and that it is activated $\mathrm{NF}-\kappa \mathrm{B}$ that drives the DHT-induced VCAM-1 expression in male cells (7), we next investigated whether increased AR in phenotypically female cells also led to NF-кB activation. HeLa cells were transfected with the AR expression vector (pSVARo) and an NF$\kappa \mathrm{B}$-luciferase reporter vector. $\mathrm{AR}$ expression increased NF-кB-luciferase activity 1.8 -fold ( $p<0.05$ vs. non-pSVARo transfected controls) (Figure 4) confirming that AR when present in high enough amounts can modulate NF- $\mathrm{KB}$ activity in female ECs.

\section{AR upregulation in female MDMs does not induce lipoprotein metabolism genes}

The accumulation of cholesteryl esters in macrophages leads to foam cell formation, a second important event in early atherosclerotic plaque formation. We have previously shown that DHT increases lipid accumulation in human monocytederived macrophages (MDMs) in a sex-specific manner, with the effect measured in male but not female cells and associated with DHT-induced expression of the lipoprotein metabolism genes ACAT1, LAL, HSL and caveolin-2 (CAV2) (9). Given the AR dependence of VCAM-1 in human endothelial cells, we tested whether the expression of the

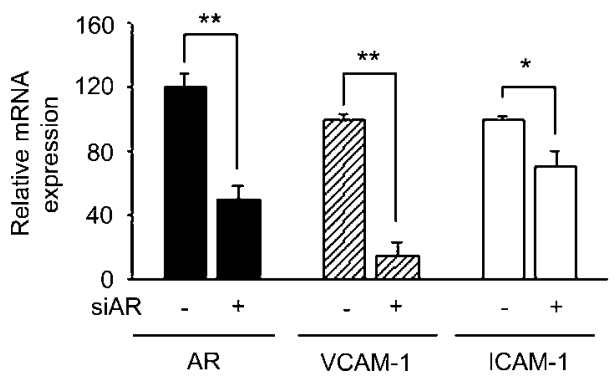

Figure 3 Silenced AR expression levels decrease VCAM-1 expression.

Total RNA was extracted from male-derived HUVECs transfected with an AR siRNA plasmid (siAR). AR, VCAM-1 and ICAM-1 mRNA levels were measured by real-time PCR. Results are expressed as mean \pm SEM of relative expression value (\%) obtained from triplicate values from a single male donor. $* \mathrm{p}<0.05$, $* * \mathrm{p}<0.005$ vs. sex-specific non-transfected control (one-way ANOVA with Bonferroni's post-hoc analysis). 


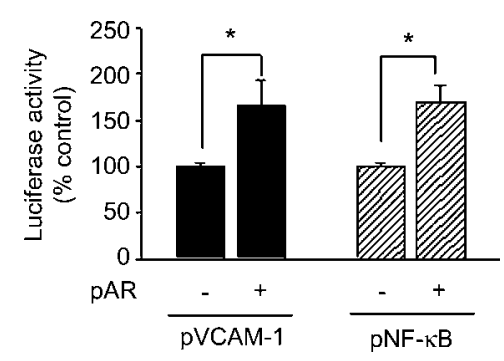

Figure 4 AR expression in $\mathrm{HeLa}\left(\mathrm{AR}^{-}\right)$cells increases NF- $\mathrm{B}$ activation and VCAM-1 promoter activity.

HeLa cells were transfected with (i) pVCAM-1-luciferase reporter vector (F2, control), (ii) pVCAM-1-luciferase reporter vector and pAR expression vector (pVCAM-1 + pAR), (iii) pNF-кB-luciferase

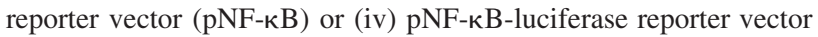
and $\mathrm{pAR}$ expression vector ( $\mathrm{pNF}-\mathrm{k}+\mathrm{pAR})$. Results are reported as mean percentage \pm SEM of cells transfected with pNF- $\mathrm{B}$ or pVCAM-1 and represent 3-5 separate experiments. *p $<0.05$ comparing pNF-кB vs. pNF-кB + pAR or pVCAM-1 vs. pVCAM- $1+$ pAR (Student's t-test).

lipid metabolism genes were similarly modulated by increasing AR levels in MDMs. Female MDMs were transfected with $\mathrm{pAR}$ and were treated or not treated with DHT (400 nmol/L, Figure 5). In female MDMs overexpressing AR there was no significant increase in ACAT, LAL or CAV-2 mRNA levels (Figure 6A-D). To test if AR required activation to increase gene transcription, transfected female cells were treated with DHT, however, no further induction was observed. HSL mRNA increased modestly upon DHT treatment but was not statistically significant (Figure 6D). In contrast, DHT treatment of non-transfected, male MDMs significantly induced transcription of all four genes (Figure 6), consistent with earlier studies (9).

\section{Discussion}

This study demonstrates that AR, activated or unactivated, can act as a molecular switch in human vascular endothelial cells to activate NF-кB thereby driving sex-specific NF-кBdependent VCAM-1 expression and monocyte adhesion, key early steps in atherosclerosis establishment. Conversely, this study has revealed that AR alone, unactivated or activated, is not sufficient for regulating the sex-specific expression of ICAM-1 in ECs or genes involved in lipid metabolism in female-derived MDMs. Increasing AR levels in MDMs from female donors did not significantly increase ACAT, LAL, HSL or CAV-2 expression, even after DHT activation, suggesting the AR could be interacting with other cofactors or nuclear factors in male cells to increase lipid metabolism genes and subsequent lipid accumulation, factors that could be missing or poorly expressed in female versus male cells.

The most striking finding of this study is that AR is acting as a molecular switch enabling or disabling proinflammatory effects in human ECs via its activation of NF-кB. It has previously been shown by our laboratory that DHT dosedependently mediates upregulation of VCAM-1 and mono-

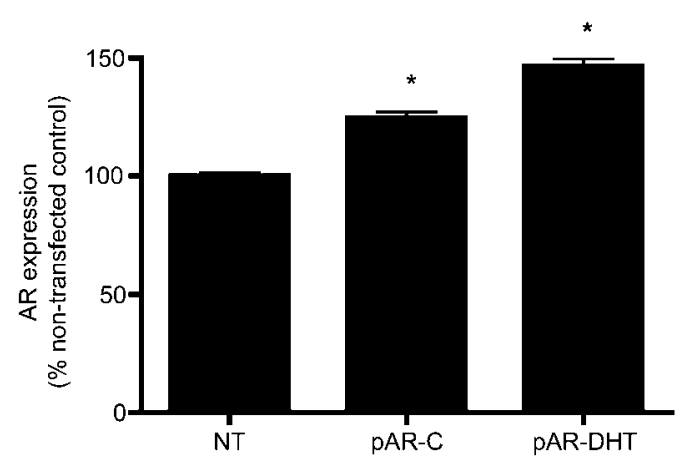

Figure 5 AR protein expression in HMDMs from female donors transfected with an AR expression vector.

HMDMs were transfected with pAR to increase AR levels. Then, $24 \mathrm{~h}$ after transfection, cells were treated with DHT (pAR-DHT; $400 \mathrm{nmol} / \mathrm{L}$ ) or vehicle control (pAR-C; $0.1 \%$ ethanol) for $24 \mathrm{~h}$. Total protein was extracted and Western blot analysis was used to measure AR levels relative to $\beta$-actin levels. Membranes were directly digitized and Quantity One was used to measure band densities. All AR levels were normalized to $\beta$-actin levels. Data are presented as mean \pm SEM. * $\mathrm{p}<0.05$ vs. corresponding control (oneway ANOVA with Bonferroni's post-hoc analysis).

cyte-endothelial cell adhesion in male cells through the AR, as the effect of DHT could be significantly abrogated by pharmacological blockade with an AR antagonist (8). Accordingly, this effect was postulated to be sex-specific owing to the higher levels of AR in male compared to female ECs (7). We have now shown conclusively that in male ECs VCAM-1 expression is dependent upon AR and demonstrate that by simply increasing AR in female endothelial cells, their behavior changes to mimic male cells. Male-specific expression of AR activates NF- $\mathrm{KB}$ and subsequently VCAM1 expression in male endothelial cells, leading to increased monocyte adhesion (7). Female cells that inherently express less AR are therefore protected from this early atherosclerotic inflammatory event. These results exclusively demonstrate the pivotal role AR plays in this androgen-induced proinflammatory, proatherogenic process. The role of AR in such proinflammatory activities and the gender-specific expression of AR could be responsible, at least in part, for the male predisposition to early onset atherosclerosis.

The finding that AR was central to the sex-specific expression of VCAM-1, but not ICAM-1, is most likely related to the key dependence of VCAM-1 expression on NF-кB (7, 11). Previous promoter-deletion studies have demonstrated the significance of the NF-кB binding site in androgeninduced VCAM-1 expression (7) and that 4-400 nmol/L DHT-stimulated AR activates NF- $\mathrm{B}$ and that it is active NF- $\kappa \mathrm{B}$ that drives DHT-induced VCAM-1 expression in male ECs. The failure of AR to induce ICAM-1 expression in female-derived cells appears not to be due to a lack of induction of NF- $\mathrm{B}$, as we demonstrated that AR can also drive $\mathrm{NF}-\kappa \mathrm{B}$ activity in phenotypically female cells. Instead, such findings could be a consequence of sex-specific expression of other nuclear factors, as ICAM-1 is regulated by multiple transcription factors acting in concert (17), or a consequence of sex differences in the expression of specific 

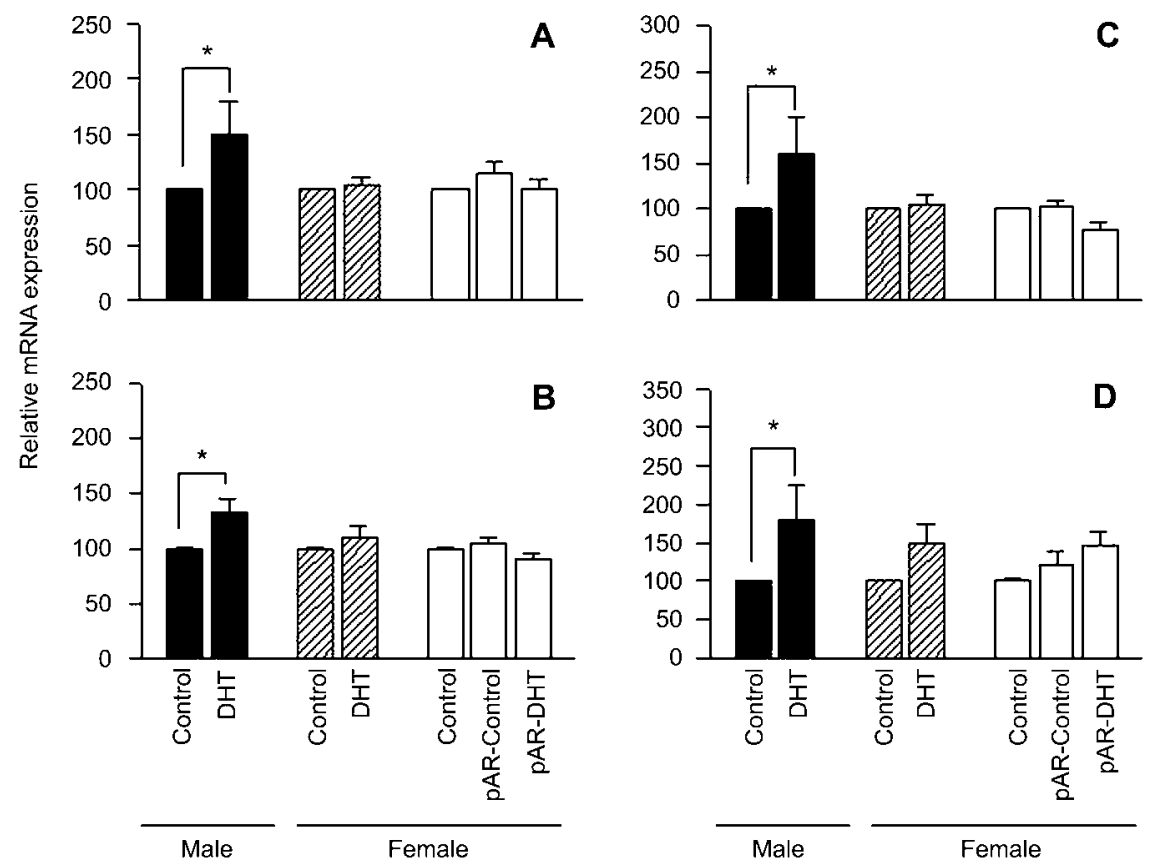

Figure 6 Sex-specific expression of lipoprotein metabolism genes in human monocyte-derived macrophages (MDMs). Non-transfected MDMs from male and female donors, and female-derived MDMs transfected with an AR expression vector (pAR) were treated with vehicle (0.1\% ethanol, control) or DHT (400 nmol/L) for $24 \mathrm{~h}$. Total RNA was extracted and mRNA expression levels of ACAT1 (A), LAL (B), CAV-2 (C) and HSL (D) were determined by real-time PCR. Results were normalized to the housekeeping gene, 18S, and expressed as mean \pm SEM $(n=3)$ relative to vehicle controls $(100 \%)$. $* p<0.05$ vs. corresponding control (one-way ANOVA with Bonferroni's post-hoc analysis).

nuclear cofactors. There is evidence for promoter-specific regulation of several NF-кB-dependent genes, including ICAM-1 and VCAM-1, coordinated by an array of NF-кB cofactors. For example, poly (ADP-ribose) polymerase-1 (PARP-1) is essential for NF-кB dependent ICAM-1, but not VCAM-1, expression in murine smooth muscle cells (18). Similarly, coactivator-associated arginine methyltransferase1 (CARM-1) exhibits promoter-specific regulation of several NF-кB dependent genes, including ICAM-1, in CARM-1 knockout cells (19). There is no evidence to date for sexspecific expression of PARP-1 or CARM-1, however, we have observed lower expression of another cofactor, p300, in immunostained sections of mesenteric arteries from female compared to male subjects (unpublished observations). p300 directly associates with PARP-1 and both p50 and p65 (RelA) subunits of NF- $\mathrm{B}$ to synergistically activate transcription (20). Acetylation of PARP-1 by p300/CBP is also necessary for coactivation of NF-кB transcription (21). Further investigation is warranted into possible gender differences in the expression of these or a growing number of cofactors that interact with the AR and/or NF- $\mathrm{B}(19,22)$ and any subsequent contribution to sex-specific inflammatory signaling.

Limiting levels of other nuclear factors could also explain the lack of induction of lipoprotein metabolism genes in female MDMs in the presence of increased levels of AR and DHT. This and previous studies show that these same genes are readily inducible by pharmacological and physiological concentrations of DHT in male cells, and inhibition by AR- specific antagonists demonstrates AR dependence (9). AR is therefore important for male regulation of the lipid metabolism genes, however, as female cells with increased AR remain unresponsive to DHT in this regard, it suggests that AR must be acting with other cofactors/nuclear factors and itself is not sufficient to drive expression of lipid metabolism genes. Like ICAM-1, transcriptional control of the lipid metabolism genes is highly complex and involves concerted combinations of transcription factors. There is evidence for an NF-кB role in LAL and HSL transcriptional control but no obvious involvement in CAV-2 or ACAT1 expression (23, 24). The androgen-sensitivity of HSL and CAV-2 in male MDMs could instead be a consequence of their regulation by the sterol regulatory element binding protein (SREBP) (23), whose activity is AR-dependent via upstream regulation of escort proteins, SCAP (SREBP cleavage activating protein) and insig-1 and -2 (25).

In summary, the data presented here show that AR acts as a molecular switch that promotes early proatherogenic processes in male ECs via NF- $\mathrm{B}$ activation. Increasing $\mathrm{AR}$ expression in female ECs increased VCAM-1 expression and monocyte-endothelial cell adhesion, unequivocally demonstrating the AR-dependence of these key early steps in early lesion development. Low expression of AR in female ECs limits VCAM-1 activation in response to androgens and could contribute to the gender bias in cardiovascular disease. Inability of $\mathrm{AR}$ overexpression in phenotypically female cells to induce other atherogenic genes suggests sex-specific expression of other transcription factors or cofactors that act 
with AR or NF-кB could also play a role in limiting vascular inflammation and early lesion development in women and deserve further study.

\section{Acknowledgements}

This work was supported by grants from the National Health and Medical Research Council of Australia and the Bruce and Joy Reid Foundation.

\section{References}

1. Kalin MF, Zumoff B. Sex hormones and coronary disease: a review of the clinical studies. Steroids 1990;55:330-52.

2. Mendelsohn ME, Karas RH. The protective effects of estrogen on the cardiovascular system. N Engl J Med 1999;340:1801-11.

3. Liu PY, Death AK, Handelsman DJ. Androgens and cardiovascular disease. Endocr Rev 2003;24:313-40.

4. Alexandersen P, Haarbo J, Byrjalsen I, Lawaetz H, Christiansen C. Natural androgens inhibit male atherosclerosis: a study in castrated, cholesterol-fed rabbits. Circ Res 1999;84:813-19.

5. Bruck B, Brehme U, Gugel N, Hanke S, Finking G, Lutz C, Benda N, Schmahl FW, Haasis R, Hanke H. Gender-specific differences in the effects of testosterone and estrogen on the development of atherosclerosis in rabbits. Arterioscler Thromb Vasc Biol 1997;17:2192-99.

6. Nettleship JE, Jones TH, Channer KS, Jones RD. Physiological testosterone replacement therapy attenuates fatty streak formation and improves high-density lipoprotein cholesterol in the Tfm mouse: an effect that is independent of the classic androgen receptor. Circulation 2007;116:2427-34.

7. Death AK, McGrath KCY, Sadar MA, Nakhla S, Jessup W, Handelsman DJ, Celermajer DS. Dihydrotestosterone promotes vascular cell adhesion molecule-1 expression in male human endothelial cells via a nuclear factor-kB-dependent pathway. Endocrinology 2004;145:1889-97.

8. McCrohon JA, Jessup W, Handelsman DJ, Celermajer DS. Androgen exposure increases human monocyte adhesion to vascular endothelium and endothelial cell expression of vascular cell adhesion molecule-1. Circulation 1999;99:2317-22.

9. Ng MK, Quinn CM, McCrohon JA, Nakhla S, Jessup W, Handelsman DJ, Celermajer DS, Death AK. Androgens up-regulate atherosclerosis-related genes in macrophages from males but not females: molecular insights into gender differences in atherosclerosis. J Am Coll Cardiol 2003;42:1306-13.

10. Ross R. The pathogenesis of atherosclerosis: a perspective for the 1990s. Nature 1993;362:801-9.

11. Mukherjee TK, Dinh H, Chaudhuri G, Nathan L. Testosterone attenuates expression of vascular cell adhesion molecule- 1 by conversion to estradiol by aromatase in endothelial cells: implications in atherosclerosis. Proc Natl Acad Sci USA 2002;99: 4055-60.
12. McCrohon JA, Death AK, Nakhla S, Jessup W, Handelsman DJ, Stanley KK, Celermajer DS. Androgen receptor expression is greater in macrophages from male than from female donors. A sex difference with implications for atherogenesis. Circulation 2000;101:224-6.

13. Cleutjens KB, van Eekelen CC, van der Korput HA, Brinkmann AO, Trapman J. Two androgen response regions cooperate in steroid hormone regulated activity of the prostate-specific antigen promoter. J Biol Chem 1996;271:6379-88.

14. Minter AJ, Dawes J, Chesterman CN. Effects of heparin and endothelial cell growth supplement on haemostatic functions of vascular endothelium. Thromb Haemost 1992;67:718-23.

15. McCrohon JA, Nakhla S, Jessup W, Stanley KK, Celermajer DS. Estrogen and progesterone reduce lipid accumulation in human monocyte-derived macrophages: a sex-specific effect. Circulation 1999;100:2319-25.

16. Bustin SA. Absolute quantification of mRNA using real-time reverse transcription polymerase chain reaction assays. J Mol Endocrinol 2000;25:169-93.

17. Degitz K, Li LJ, Caughman SW. Cloning and characterization of the 5'-transcriptional regulatory region of the human intercellular adhesion molecule 1 gene. J Biol Chem 1991;266: 14024-30.

18. Zerfaoui M, Suzuki Y, Naura AS, Hans CP, Nichols C, Boulares AH. Nuclear translocation of p65 NF- $\mathrm{B}$ is sufficient for VCAM-1, but not ICAM-1, expression in TNF-stimulated smooth muscle cells: differential requirement for PARP-1 expression and interaction. Cell Signal 2008;20:186-94.

19. Covic M, Hassa PO, Saccani S, Buerki C, Meier NI, Lombardi C, Imhof R, Bedford MT, Natoli G, Hottiger MO. Arginine methyltransferase CARM1 is a promoter-specific regulator of NF-кB-dependent gene expression. EMBO J 2005;24:85-96.

20. Hassa PO, Buerki C, Lombardi C, Imhof R, Hottiger MO. Transcriptional coactivation of nuclear factor- $\kappa \mathrm{B}-$ dependent gene expression by $\mathrm{p} 300$ is regulated by poly(ADP)-ribose polymerase-1. J Biol Chem 2003;278:45145-53.

21. Hassa PO, Haenni SS, Buerki C, Meier NI, Lane WS, Owen H, Gersbach M, Imhof R, Hottiger MO. Acetylation of poly(ADPribose) polymerase- 1 by $\mathrm{p} 300 / \mathrm{CREB}$-binding protein regulates coactivation of NF- $\mathrm{BB}-$ dependent transcription. J Biol Chem 2005;280:40450-64.

22. Perkins ND. Achieving transcriptional specificity with NF-кB. Int J Biochem Cell Biol 1997;29:1433-48.

23. Laurencikiene $J$, van Harmelen V, Arvidsson Nordstrom E, Dicker A, Blomqvist L, Naslund E, Langin D, Arner P, Ryden M. NF-кB is important for TNF- $\alpha$-induced lipolysis in human adipocytes. J Lipid Res 2007;48:1069-77.

24. Ries S, Buchler C, Langmann T, Fehringer P, Aslanidis C, Schmitz G. Transcriptional regulation of lysosomal acid lipase in differentiating monocytes is mediated by transcription factors Sp1 and AP-2. J Lipid Res 1998;39:2125-34.

25. Heemers HV, Verhoeven G, Swinnen JV. Androgen activation of the sterol regulatory element-binding protein pathway: current insights. Mol Endocrinol 2006;20:2265-77. 